\title{
Passenger-Centric Factors Influencing the Experience of Aircraft Comfort
}

\begin{abstract}
Enhancing passenger comfort in an air cabin environment is uniquely challenging. Air travel offers a restrictive passenger experience in terms of available space and the ability to change one's position or journey. The first step to designing experiences for comfort is to take a broader view of the factors which influence in-flight comfort. While many studies have considered the design and services of aircrafts and airlines, this review focuses on the passenger and the internal and external factors which can affect their comfort. We present a descriptive model of comfort that comprises factors such as individual characteristics, personal travel context and interaction with others. This model could be used to develop an improved aircraft passenger experience.
\end{abstract}

Keywords: aviation; passenger comfort; aircraft passenger comfort model, air transport, comfort

\section{Introduction}

Air travel can be a comfortable experience, however comfort often comes at a cost to the various stakeholders involved - passengers, airport operators, airlines and aircraft manufacturers. Changing the physical parameters such as seating and lighting in commercial aircraft to increase comfort is difficult due to physical and safety restrictions, cost, regulations and reduction in passenger capacity. The challenge is to find ways of enhancing the flight experience with minimal changes to the physical cabin environment. Rather than the design of the air cabin and airline services, this paper focuses on how passengers contribute to their own comfort. We provide a broader view of passenger comfort, drawing from relevant literature in a number of domains, to describe factors which should be considered when designing for, or evaluating, on-board comfort.

\section{Comfort and discomfort}

\subsection{Defining Comfort}

For a term so widely used in everyday language, there is considerable debate on the exact definition and understanding of comfort, its components, and its relationship to discomfort. At a basic level, comfort is about meeting people's needs and is a desirable outcome or the optimum state for a given context. Each individual has different needs, and their experience of comfort is subjective, influenced by internal or personal factors as well as external stimuli.

A recent definition of comfort was based on De Looze, Kuijt-Evers, and Van Dieen's (2003) and Helander and Zhang's (1997) definitions: "Comfort is seen as a pleasant state or relaxed feeling of a human being in reaction to its environment" and "Discomfort is seen as an unpleasant state of the human body in reaction to its physical environment" (Vink \& Hallbeck, 2012, p.271). 
Others have defined comfort simply in terms of it being a state without discomfort, suggesting that comfort is a neutral feeling (Hertzberg, 1958). However, while Vink and Brauer (2011) agree that sometimes people do not experience anything (i.e. absence of discomfort), they argue that this does not imply comfort-comfort results when people experience more positive things than expected.

Many researchers have examined comfort and discomfort associated with sitting. For example, Helander and Zhang (1997) found comfort was related to feelings of well-being and the aesthetic qualities of the chair and discomfort was associated with biomechanics and fatigue. Comfort was also associated with plushness, softness, luxury (Helander \& Zhang, 1997; Zhang, Helander, \& Drury, 1996) and spaciousness (1996). In other domains, such as the built environment, comfort has been considered mainly in terms of meeting individuals' physiological needs (Cole, Robinson, Brown, \& O’Shea, 2008; Fanger, 1970).

Comfort is therefore a complex and dynamic construct, with person-centricphysiological, physical, psychological and social elements - as well as environmental and situational elements. Although there are different parameters that contribute to the sensation of comfort, in our view the experience of comfort itself is always psychological. In a flight context, different aspects of a flight experience may contribute to differing levels of comfort or discomfort in each passenger (Vink, Bazley, Kamp, \& Blok, 2012).

\subsection{Aircraft passenger comfort}

There are few published papers on aircraft passenger comfort, although it is likely that individual airlines conduct their own studies (e.g. Bird, 2011). These findings are not in the public domain due either to competition within the industry or no perceived benefits of disseminating the results (Vink \& Brauer, 2011).

Increasingly, larger airlines are focusing on comfort, having realised its importance in capturing and retaining customers. For example, Richards, Jacobson, and Kuhlthau (1978) found that lower passenger comfort ratings were associated with less willingness to fly again. Passenger comfort has also become a focus in cabin design (Airbus, 2013) and at aircraft interior trade fairs (Aircraft Interiors Expo, Aircraft Interiors International and Passenger Experience Conference).

While there is a lack of literature on passenger comfort per se, one area of focus has been on maintaining and enhancing service quality (Chou, Liu, Huang, Yih, \& Han, 2011) to attract and retain consumers (Chang \& Yeh, 2002). The SERVQUAL scale measures perceived service quality within five distinct dimensions: reliability, assurance, tangibles, empathy and responsiveness (Parasuraman, Zeithaml, \& Berry, 1988). SERVQUAL has been used to measure perceived airport and airline service quality based on tangible aspects (e.g. equipment, facilities, employees and other consumers) and on consumers' experience of intangible aspects (e.g. courtesy, responsiveness and brand image) (Parasuraman, Zeithaml, \& Berry, 1985; Santos, 2002).

A recent model of passenger comfort included contextual features categorised as "ambient" environment (e.g. temperature), "dynamic" environment (e.g. turbulence and inflight entertainment (IFE)), "spatial" environment (e.g. seat and legroom), "social features" 
(e.g. neighbours) and "passengers' activity" (Ahmadpour, Lindgaard, Robert, \& Pownall, 2014a). These features were associated with one or more of the following eight comfort themes derived from an analysis of qualitative data from passengers: "peace of mind, physical well-being, proxemics, pleasure, satisfaction, aesthetics, social and association" (2014a, p.804). Ahmadpour et al.'s model indicated that contextual factors interacted with factors related to the individual (e.g. their expectations) to induce perceptions of comfort or discomfort, and potentially also a physical impact, which could subsequently influence their expectations of, and behaviours in, future flights.

Ahmadpour, Robert, and Lindgaard (2014b) further identified four emotion categories that may inform perceived comfort: "well-being" emotions (e.g. feeling good/bad), "prospectbased" (e.g. disappointment/relief), "well-being/attribution compound" (e.g. gratitude/anger) and "attraction" emotions (e.g. like/dislike) (2014b, p391). These emotions were associated with expected or unexpected context features, i.e., service, seat, legroom, IFE and neighbours. The authors stated that their participants' comfort experience was focused on how they personally felt and not on how other people felt.

It has been suggested that aircraft passengers' comfort can be studied in different phases: by influencing expectations (e.g. through airline websites); first sight comfort (e.g. attractive aircraft interior); short-term comfort (e.g. enhanced by attentive crew); short-term discomfort (e.g. managed with a good seat which does not create pressure points); long-term comfort (e.g. enhanced by the ability to perform desired activities); and long-term discomfort (e.g. minimised by supportive seats) (Vink \& Brauer, 2011).

Mayr's (1959) model of riding comfort developed for the rail domain is also of relevance to air travel. It incorporates the physiological and psychological aspects (including eagerness or fear) influencing the comfort experience within a vehicle as well as technical and sensory factors. The model comprises the following factors: interior design; running characteristics (e.g. noise and vibrations); general installations (e.g. sanitation and catering) and atmosphere (e.g. heating, ventilation and lighting). However, as Oborne (1978) notes, Mayr does not include passengers' activities in his model.

In this paper we consider in-flight comfort from a passenger-focused perspective discussed in relation to the following factors: individual characteristics; personal travel context; preflight and in-flight environments; interaction with others; activities; current state, needs and adaptive behaviour; and perceived control. By understanding these factors, airlines and aircraft manufacturers can better design air cabins to enhance passenger comfort.

\section{Factors Influencing In-flight Comfort}

\subsection{Individual Characteristics}

The passenger comprises a number of unique factors: demographic (e.g. age, nationality, income); physical (e.g. body size); physiological (e.g. blood pressure); state of health and general wellbeing; psychological (e.g. perception, attention, cognition, fears, personality, mood, affect, etc.) coupled with historical and psychological experiences (memory of previous flights), expectations about future experiences and personal preferences; 
predispositions and sensitivities (e.g. to motion sickness or noise); and whether they are frequent flyers (Bor, 2007; Budd, 2011; Quehl, 2001; Richards et al., 1978). The flight environment can interact with, or influence, these factors and these factors can affect the perception of the environment; they may also influence how people respond to and cope with stress (Bor, 2007; Vink \& Brauer, 2011). These factors may directly or indirectly affect the comfort experienced during a flight (Richards et al., 1978), for example, someone with a high salary can afford more comfortable first class travel.

The factors outlined above include those that are difficult or impossible to change, for example, some demographics (sex and height), passengers' personalities and also their past experiences. It is however possible for people to think about their past experiences in a different way and thus change their experience of comfort in future flights. It is also possible to change passengers' current perceptions, expectations, beliefs, attitudes, behaviour, states (physical, psychological and physiological), as well as their pre-flight experiences.

Individual variability in the psychological factors influencing comfort can affect how environmental conditions are perceived as well as behaviour in those conditions (Bor, 2007; Brager \& de Dear, 2000; Quehl, 2001; Richards et al., 1978). For example, Richards et al. (1978) found that people who liked flying, rated it as being more comfortable than people who did not like to fly or who had no preference either way; the sex of the passenger and the number of previous flights taken were unrelated to attitudes to flying and neither was the number of previous flights to comfort ratings. They concluded that attitudes are an important moderating factor of comfort because people who dislike flying are more likely to selectively attend to the negative aspects of flying which are consistent with their overall views of air travel.

Expectations of journey comfort and prior experience are also likely to influence actual comfort (Oborne, 1978). When judging service quality, people tend to expect to get what they pay for, for example, Blok, Vink, and Kamp (2007 as cited in Vink \& Brauer, 2011) found that a business class seat and economy class seat were rated the same in terms of comfort because business passengers had higher expectations. Similarly, Bhadra (2009) found that lower fares were associated with fewer complaints over flight delays. Passengers' educational background influenced expectations and perceptions of a Turkish airline's services - the higher the level of education, generally the lower the perception of service quality (Pakdil \& Aydin, 2007). Individual preferences for different product/experience features may also play an important role in influencing comfort.

A passenger's physical and psychological characteristics and/or current state of health are also likely to influence their comfort and can possibly lead to adverse health outcomes. For example, in a study by Vink et al. (2012), taller passengers $(>173 \mathrm{~cm})$ gave lower legroom comfort ratings than shorter passengers. There may also be sex differences in the level of comfort experienced. In Richards et al.'s (1978) study, women reported finding a commuter flight more comfortable than men. The women did not fly as frequently as men, were less likely to be business travellers, and rated motion inputs as influencing their comfort the most. There was no difference between men and women's comfort ratings associated with motion, however women gave higher comfort ratings to their seat, which explained their greater overall flight comfort (1978). Differences in size between men and women may also have played a role in their comfort, however this was not directly examined. 
Accommodating overweight and obese passengers presents a contentious issue for airlines due to several conflicting requirements which should be considered: the comfort, safety and experience of the obese passenger, neighbouring passengers and crew; stigmatisation of obese passengers; pricing discrimination; ethical and fairness issues; health concerns as well as the economic cost to airlines (Harris \& Small, 2009; Howe, 2016; O’Neill, 2004; Scurr, Ahmad, Thavarajan, \& Fisher, 2010; Small \& Harris 2012). Many airlines have 'Customer of Size' policies which dictate that an additional seat must be purchased if passengers cannot fit into one seat (Veldhuis \& Holt, n.d.).

People may have preferred coping strategies to adjust to environmental stressors with differing levels of success (Evans \& Cohen, 1987; Richards et al., 1978). Some people may easily habituate to their environment, whereas for others, certain stimuli may remain focal points without some form of distraction. Passengers' demographic background may also play an important role in their experience, for example, cultural background may affect expectations about what is acceptable in terms of comfort and is likely to shape experiences in specific contexts (Cole et al., 2008). Some passenger needs may be rooted in cross-cultural differences associated with particular values or behaviours, leading to specific requirements for the environment, IFE and catering (Prideaux \& Seongseop, 2006). Conflicting behaviours may cause discomfort for passengers from different cultural backgrounds. For example, on flights through Japan, Korean passengers showed a tendency to be noisy and not comply with the cabin crew's instructions, whilst Japanese passengers tended to be quiet and were more likely to follow the crew's guidance (2006).

There are also cross-cultural differences in the perceived importance of different aspects of an airline's service and their impact on passengers' satisfaction (Horner \& Swarbrooke, 2004); for example, a study found that Japanese and Chinese passengers had higher expectations of IFE than West European and North American passengers (Gilbert \& Wong, 2003).

Airlines recognise the importance of profiling real passengers instead of relying on stereotypical notions of customer needs. For example, an Air New Zealand project aimed to gain a detailed understanding of their passengers' requirements which led to a change in focus from "selling seats to selling experiences" (Bird, 2011, p.42), defining both functional and psychological needs to inform the design of new experiences, such as ways to adapt seats to support the needs of people travelling together.

\subsection{Personal Travel Context}

The personal travel context includes the purpose of the trip, who paid for it, flight duration, delays, chosen airline and its brand image, whether the passenger is travelling alone, and all the experiences leading up to boarding the plane. Such factors and experiences can be a cause of anxiety before even boarding the flight and may influence overall comfort and possibly behaviour during the flight itself (Bor, 2007; Oborne, 1978; Vink \& Brauer, 2011). For example, Konieczny (2001) found that trust in the airline as defined by its image and reputation had a greater influence on comfort than the aircraft manufacturer's image. Furthermore, passenger choices may directly affect their comfort: leisure travellers often select the cheapest airline, irrespective of seat pitch, whereas business travellers may value increased seat pitch more (Lee \& Luengo-Prado, 2004). 
Flight duration is likely to be an important determinant of comfort. Passengers may be more accepting of discomfort on shorter flights than during longer flights; therefore comfort provisions are likely to be more important on long flights. Vink and Brauer (2011) found that passengers reported lower comfort scores when flying for four hours, however, for flights over five hours mean comfort scores increased. The authors suggest that this finding could be attributed to greater comfort on board wider body jets used for long haul flights. In support of this, Balcombe, Fraser, and Harris (2009) found that passengers were willing to pay more for better service and comfort on flights of between 4.5 to 5.5 hours. Similarly, Blok et al. (2007 as cited in Vink \& Brauer, 2011) found that the IFE and cabin crew service were more important in influencing comfort for flights over five hours.

Of relevance to personal travel context is the 'aeromobilities' domain which is concerned with the role of air travel in society, encompassing social, cultural, political, economic, urban, environmental, technological, legal and security dimensions of the air transportation system as well as the supporting airspace and infrastructure, including the weather (Adey, 2008; Budd, 2011; Cwerner, Kesselring, \& Urry, 2008). This multi-dimensional approach sees air travel as central to modern social life (Cwerner et al., 2008). There is also a focus on the human aspects of aeromobilities systems, such as the socioeconomic backgrounds of potential travellers and the impact of aeromobilities systems on different segments of the population, their motivations to fly, the role of air travel in everyday life and its role in establishing and maintaining social, personal and business relationships across distances (Cwerner et al., 2008).

Adey and Lin (2014) discuss the concept of 'entubulation' which views the air cabin as a cocoon that is decoupled from the physically moving aircraft. This entubulated space has been adapted by airlines, evolving over time and tailored to customers across space, to create specific cultural and social contexts. These spaces are designed to enhance passenger comfort and their perception of service. Some airlines embrace cultural stereotypes and cultivate their brand image through the cabin crew's attire and their emotive attention to specific passengers' needs and expectations - Adey and Lin give the example of the iconic 'Singapore girl' who is tasked with conveying Oriental grace and charm in her interactions with Western passengers.

The entire aeromobility system is capable of influencing passengers' comfort; in our model, many of these aspects are represented within individual characteristics, personal travel context, interaction with others and the pre-flight and in-flight environments.

\subsection{The Pre-flight and In-flight Environments}

Although factors indirectly associated with the passenger are not the focus of this paper, the pre-flight and in-flight environments must briefly be mentioned as they play an important role in overall flight comfort. The pre-flight environment refers to the overall airport experience (e.g. checking-in and security) which can influence the experience of comfort or discomfort on an aircraft (Konieczny, 2001; Richards \& Jacobson, 1974; Vink \& Brauer, 2011).

The in-flight environment includes the aircraft's physical space and seats (Brundrett, 2001; Budd, 2011; Hinninghofen \& Enck, 2006; Konieczny, 2001; Vink et al., 2012; Vink \& Brauer, 2011); sensory factors (e.g. motion inputs, noise, vibration, light, temperature, air quality, pressure etc.-Hinninghofen \& Enck, 2006; Pennig, Quehl, \& Rolny 2012); facilities, cleanliness, announcements/information, personal equipment (Vink \& Brauer, 2011); 
interaction with fellow passengers and the cabin crew (Budd, 2011; Quehl, 2001; Vink et al., 2012); and entertainment (Budd, 2011).

After boarding the aircraft, the in-flight environment will interact with passengers to influence their well-being (Hinninghofen \& Enck, 2006). For example, the amount of personal space available may influence their comfort. Personal space boundaries can be affected by factors such as individual differences, cultural background, interpersonal relationships and context (e.g. Hayduk, 1983; Little, 1965; Sommer, 1959; Sommer, 2002) the invasion of this boundary is often a source of discomfort.

Some in-flight stimuli may have more influence on comfort or discomfort than others and factors may also interact to influence passenger experience. For example, Vink and Brauer (2011) note that a bad smell may override any comfort being experienced. Environmental factors may influence comfort directly or indirectly by affecting passengers' ability to perform activities (e.g. vibrations may make it more difficult to eat or read and may contribute to eye fatigue) (Richards et al., 1978). Sensory environmental factors which potentially affect comfort may also interact with each other, for example, an increase in noise may draw attention to aircraft motion (Oborne, 1978; Quehl, 2001) or increase awareness of swollen feet or neck pain (Mellert, Baumann, Freese, \& Weber, 2008). Different durations of exposure to environmental stressors also have a varying influence on individuals' physical, physiological and psychological well-being (Evans \& Cohen, 1987).

\subsection{Interaction with Others}

The presence of, and interaction with, the cabin crew as well as other people could influence passenger comfort and flight experience both prior to boarding and during the flight (Quehl, 2001; Vink et al. 2012; Vink \& Brauer, 2011). This interaction includes conversing with others and being subjected to other people's appearance, conversations and behaviour (Budd, 2011). Others' behaviour can cause greater stress and annoyance (as it could be modifiable) than exposure to natural stimuli (e.g. heat), which are accepted as being less easy to change (Evans \& Cohen, 1987).

Studies have tended to focus on how airline ground staff and cabin crew affect comfort and satisfaction (Bor, 2007). For example, genuine expressions such as authentic smiles from cabin crew were correlated with higher overall service satisfaction and perception of their care for passengers (Gountas, Ewing, \& Gountas, 2007). Similarly, Suki (2014) found that company/employees' empathy positively influenced passengers' satisfaction; in contrast, tangible features (e.g. cleanliness, seats, interior design) did not influence satisfaction. The empathy element (e.g. personal attention) of service quality influences passengers' attitudes, cognition and affect (Parasuraman et al., 1988; Suki, 2014). A cabin crew's knowledge and behaviour were also found to be important to passengers assessing service quality, and could reduce anxiety (Chen \& Chang, 2005). With regard to actual satisfaction with service features in Chen and Chang's study, passengers rated cabin crew appearance and courtesy, and the safety demonstration as barely satisfactory.

Social comfort refers to the relationship of an individual's personal space to others' personal space, privacy, interaction and a group's shared understanding of comfort (Cole et al., 2008). As such, "personal comfort may be compromised consciously or unconsciously for the greater good of collective comfort" (Cole et al., 2008, p.333). For example, individuals 
may refrain from reclining their seats in order to increase personal comfort, as this would reduce the comfort of passengers behind them.

Social comfort can be affected by whether people are travelling alone or with others, whether the adjacent seat is occupied, whether they are next to someone familiar, and the location of their seat. Vink and Brauer (2011) found that passengers sitting without a neighbour or with just one other person next to them reported higher comfort scores. Other passengers' comfort could be increased for example by staying within the boundaries of one's seat and responding appropriately to social cues (signalling desired or undesired interaction). A notable omission in the current literature (with the exception of a small study by Ahmadpour, Kühne, Robert \& Vink, 2016) is consideration of whether passengers are travelling alone or with other people, which is surprising considering the different ways this could affect comfort.

Individuals can be subjected to undesired interaction or noise from neighbouring passengers which may affect their ability to perform desired activities; moreover, the thoughtlessness of others may be annoying (Elliott, 2012; Fiorella, 2011). Interestingly, the passenger types described on the internet by travel journalists, flight attendants and passengers, generally relate to the negative perception of others, such as unruly children (Cronian, 2009), the ill-mannered (Burns, 2008), oversized passengers (Crowe, 2010) and personal space invaders (Andrews, 2010), though there is likely to be a bias towards writing about the worst fellow passengers rather than the best ones.

\subsection{Activities}

Activities refer to what passengers do on a plane, such as resting, working or engaging in entertainment. These activities may involve personal equipment or equipment/amenities provided as part of the in-flight service. Expectations may be moderated by pre-planning, such as, packing a book to read which can subsequently influence the experience of comfort.

Passengers may engage in activities to distract themselves from feelings of discomfort; if they are sufficiently immersed in an activity they are less likely to notice discomfort (Richards et al., 1978). Researchers have acknowledged the power of distraction as a moderator of discomfort and pain (Butler \& Moseley, 2003; Dahlquist et al., 2007; Howarth $\&$ Bullimore, 2005). Therefore the level of comfort experienced when performing an activity may also be related to whether it is being carried out for pleasure (e.g. watching a film) or whether it is required (e.g. preparing for a meeting) (Richards et al., 1978).

Activities may be easy or difficult to do depending on factors associated with the in-flight environment (Ahmadpour et al., 2014a; Quehl, 2001; Richards et al., 1978) as well as other factors such as the passenger's current state (e.g. ear discomfort caused by cabin pressure may affect a passenger's ability to hear the IFE) or the behaviour of neighbouring passengers. Ambient environmental stressors may not be noticed until they prevent individuals from achieving their goals (Evans \& Cohen, 1987), for example, engine noise may interfere with the ability to hear a film's dialogue. Discomfort may be experienced when passengers are distracted from, or are unable to perform, their activities (Oborne, 1978). 
The activities that passengers carry out may interact with their assigned physical space and their ability to adapt the space accordingly (e.g. Han, Jung, Jung, Kwahk, \& Park, 1998). Relaxing and sleeping are preferred in-flight activities, followed by being entertained; however it is likely that relaxing and sleeping will be harder to do in economy class due to the restricted seat configuration (Alamdari, 1999). At times, a certain level of comfort may be necessary in order to perform activities - in Richards et al.'s (1978) study, difficulty sleeping, writing, reading and concentrating was correlated with flight comfort ratings. The authors suggest, for example, that writing may be difficult due to an aircraft's motion.

\subsection{Current State, Current Needs and Adaptive Behaviours}

A passenger's current state at any one time encompasses physical, physiological, psychological, social and behavioural well-being, including comfort, discomfort and satisfaction. This state impacts on the passenger's needs and influences their subsequent adaptive behaviours to change their state. The current state is a result of the complex processes of perception, physiological mechanisms, and cognitive reappraisal of the personal context and their general and immediate environment. Other researchers have also highlighted the key role of physical, physiological and psychological factors in the experience of comfort (Ahmadpour et al., 2014a).

There are a number of health concerns which can be triggered or worsened by flying, such as motion sickness, ear discomfort, anxiety and deep vein thrombosis (DVT-when a blood clot develops in a deep vein, which can occur after prolonged physical inactivity such as during a long flight) (Bor, 2007; Budd, Warren, \& Bell, 2011). Some people may be predisposed to negative effects in-flight, however even healthy individuals may suffer from adverse effects when subjected to sub-optimal factors - which may also interact - that make up the in-flight environment in journeys over 12 hours (Hinninghofen \& Enck, 2006).

Fears and anxieties may be present prior to boarding the plane and passengers can respond to these in a multitude of ways, by becoming aggressive, exhibiting disruptive behaviour or withdrawing (Bor, 2007). They may also exhibit strong emotional responses to invasion of their personal space (Bor, 2007). More positively, some people enjoy flying and can experience excitement from seeing the view outside (Budd, 2011) or from anticipating their destination.

Physical discomfort is not simply due to sitting in a particular seat for hours. Physical, sensory and physiological input is moderated by cognitive and affective processes in addition to passenger characteristics (e.g. general wellbeing, anxiety, previous experience, expectations, cultural factors) and the social environment, which can influence the perception of comfort or discomfort-its presence or absence and the degree of discomfort experienced (Butler \& Moseley 2003; Corlett, 2005; Howarth \& Bullimore, 2005; Richards et al., 1978; Vink \& Brauer, 2011).

Whilst on board, the current state of the passenger (e.g. levels of anxiety, fatigue, hydration etc.), the in-flight environment, interaction with others, the activities being carried out, level of perceived control, individual needs and the ability to adapt to the environment are in a state of flux. The experience of comfort may be transient: passengers may not be aware of feeling comfort or discomfort, or may fleetingly register these feelings before habituating or 
distracting themselves from discomfort; in addition, feelings of comfort have the potential to change into feelings of discomfort and vice versa.

Passengers' changing needs throughout a flight have received little attention in the literature. At any given time, passengers have particular needs: activity-related, social, psychological, physiological or physical. These needs may interact with each other (needing quietness to watch a film) and they may conflict with the requirements of the crew (needing the passenger to stop their activity during meal times).

Some passengers may plan activities they want to perform during the flight and already know which needs they would like met before flying; others may plan after boarding; alternatively, there may be no prior planning, with activities and needs emerging and changing unpredictably during the flight. The extent to which passenger needs are met will influence their (changing) experience of comfort and discomfort during the flight.

Passengers may adopt strategies or change their behaviour in order to reduce discomfort or increase comfort, for example, by moving around the cabin or seeking social interaction. Individuals can subconsciously adapt to potential discomfort, for example, by adjusting their posture to reduce discomfort associated with a seat (Cascioli, Heusch, \& McCarthy, 2011; Helander \& Zhang, 1997). However, discomfort will be felt when a seat's design does not allow individuals to perform subconscious adaptive behaviours, or when problems with the seat design negate the benefits of those behaviours (2011).

For environmental comfort Leaman $(1999$, p.1) states that people are only compelled to use available controls after a particular event has occurred or when they experience a "crisis of discomfort" (which typically involves a lengthy wait) and often over-react to minor irritations. People do not seem to anticipate discomfort prior to reaching this "crisis of discomfort". Other adaptive responses to being in a sub-optimal environment or state include problem-focused, emotional and behavioural responses (e.g. changing clothing or having a cool drink when too hot), physiological responses (acclimatising to the environment) and psychological adjustments (e.g. changing expectations) (Brager \& de Dear, 2000; Brager, Paliaga, \& de Dear, 2004; Evans \& Cohen, 1987; Langevin, Wen, \& Gurian 2012; Nikolopoulou \& Steemers, 2003).

On trains, passengers have been observed to defend personal space through adaptive distancing or avoidance behaviours (Fried \& DeFazio, 1974). However on planes, conserving personal space becomes particularly difficult when sitting in a middle seat, as there are fewer behavioural options available to adapt to this (Evans \& Wener, 2007). Furthermore, air passengers may have to endure invasions of their personal space for long durations.

Adaptive behaviours may sometimes be subconscious when personal space is invaded (Little, 1965). However, at other times, people may consciously choose strategies to accommodate this. People often have limited options available to change their body position or orientation relative to another person and therefore may try to adapt to their environment in other ways; for example, by using music to reduce personal space boundaries (TajaduraJiménez, Pantelidou, Rebacz, Västfjäll, \& Tsakiris, 2011). Public transport users often use headphones as a cue to indicate that they do not wish to engage in social interaction, which may also reduce personal space boundaries. 
Some passengers may choose a more direct method of controlling their available personal space on a plane. For example, use of the 'knee defender' (a device that attaches to the tray table) prevents others from reclining their seatback, allowing one passenger to improve his/her comfort at the possible expense of another passenger's comfort. Its use has led to a flight being diverted and two passengers being escorted off a plane: one passenger had wanted to recline her seat but the passenger behind her was using a knee defender and refused to remove it, causing an argument (Gardner, 2014). Whilst the product is legal (as it does not have an impact on passenger safety), some airlines have prohibited its use (Roberts, 2014) and others have avoided the issue by installing seats that do not recline.

Due to the differences in service provision, economy class passengers may have to rely more on psychological adaptive behaviours to overcome discomfort than first class passengers. On a similar note, Alamdari (1999) remarked on the importance of entertainment in economy class during long haul flights, as the seats are less conducive to activities such as relaxing.

Adaptive behaviours may start prior to the flight itself, through choice of airline and plane type (which can affect motion sickness-Richards et al., 1978), cabin class and seat. For example, an aisle seat offers greater personal control (Leaman, 1999); choosing a seat over the wings can reduce motion sickness as can night flights due to less visual stimulation (Hinninghofen \& Enck, 2006); and chewing gum can counter ear ache (Budd, 2011).

Airlines also suggest behaviour to counter the negative effects of air travel. In a study of in-flight magazines and health advice given to passengers, Budd et al. (2011) found that some airlines provide information on exercises for seated positions and advise walking to increase circulation, reduce discomfort and the risk of DVT; and most airlines also encourage hydration.

\subsection{Perceived Control}

Perceived control refers to the control that passengers feel they have over meeting their needs, for example, by changing their environment, their interactions with others, their ability to perform activities and their physical and mental state. One of the comfort themes that emerged from Ahmadpour et al.'s (2014a) passenger experience data was 'proxemics' which describes passengers' perceived autonomy, control and privacy within the boundary of their personal space. Perceived control over the choice to fly may also influence comfort, for example, people who did not feel they had to fly were more positive in their attitude towards flying than those who reported that they had to fly (Richards et al., 1978).

Perceived control is associated with the physiological and psychological aspects of comfort and well-being; in other domains, increased perceived control has been associated with reduced anxiety (Bonetti et al., 2001) and lower cortisol response (i.e. reduced stress response-Abelson, Khan, Liberzon, Erickson, \& Young, 2008). Increasing perceived control can lead to psychological adjustment; enhance people's ability to deal with fears and anxiety or change their mood or behaviour; change the way they feel about a situation; help them to adapt to the environment (Cole et al., 2008; Mardiyono, Praneed Songwathana, \& Wongchan Petpichetchian, 2011; Nikolopoulou \& Steemers, 2003); enable them to perform activities (Ahmadpour et al., 2014a); and enhance their ability to change comfort levels (e.g. 
having the option to use an eye mask to block out light or watch a film to reduce anxiety). In contrast, uncontrollable environmental stressors are associated with greater stress (Evans \& Cohen, 1987).

A study from the built environment domain found that perceived control to improve thermal conditions was positively correlated with comfort (Langevin et al., 2012). In contrast, lower perceived control reduced tolerance to 'slightly cool' conditions, which would usually be associated with comfort; more importantly, the overall satisfaction with perceived control was most strongly associated with comfort (2012). Further, perceived control over multiple factors (e.g. temperature, ventilation and solar shading) has been associated with greater overall comfort in an office environment (Boerstra, Beuker, Loomans, \& Hensen 2013).

Boerstra et al. (2013) also found that perceived control over noise in indoor environments was associated with greater comfort. This research supports Leaman's (1999) view that perceived personal control is fundamental to comfort. In an aircraft setting, this could mean that simply having the functionality to adjust different parts of the seat and other aspects of the flight experience (e.g. IFE) may increase comfort.

Finally, some researchers have stressed the importance of accurate and timely in-flight information (Vink \& Brauer, 2011). Passengers are not in control of the flight itself - this control belongs to the pilots and hence accurate and trustworthy information about the flight from the crew may reduce the stress associated with this lack of control (Konieczny, 2001).

\section{Towards A New Model of Aircraft Passenger Comfort}

We present a model of aircraft passenger comfort (Figure 1) based on literature investigating comfort and discomfort in domains such as air transport, ergonomics, psychology, and built environment research. This informal, descriptive model highlights the key factors which constitute or influence passenger comfort, forming a basis to structure the comfort experience. The passenger is represented in the centre of the model including their individual characteristics and perceived control over meeting their needs - both of these, the contextual factors (pre-flight and in-flight environments and personal travel context), activities and interaction with others can potentially interact with each other, or directly influence a passenger's current state, their needs and adaptive behaviours.

For example, limited legroom in addition to a noisy neighbour may affect a passenger's ability to perform a desired activity, such as rest, which can affect their overall comfort. At any one time, an individual may be in an optimal or sub-optimal physical, physiological or psychological state which may influence their 'current needs'. If an individual develops a sub-optimal state they may consciously or subconsciously perform adaptive behaviours or engage in specific activities to achieve a more comfortable state and/or meet current needs.

The model also shows that an individual's pre-flight and in-flight experiences become part of their historical experiences and memories (within "individual characteristics"), which can potentially change their attitudes and expectations of future flights.

With further empirical work, it may be possible to assign weightings in terms of importance to comfort to the different factors in our model which can present opportunities to 
influence comfort at different levels, for example, people may tolerate less than ideal situations if their psychological needs are met.

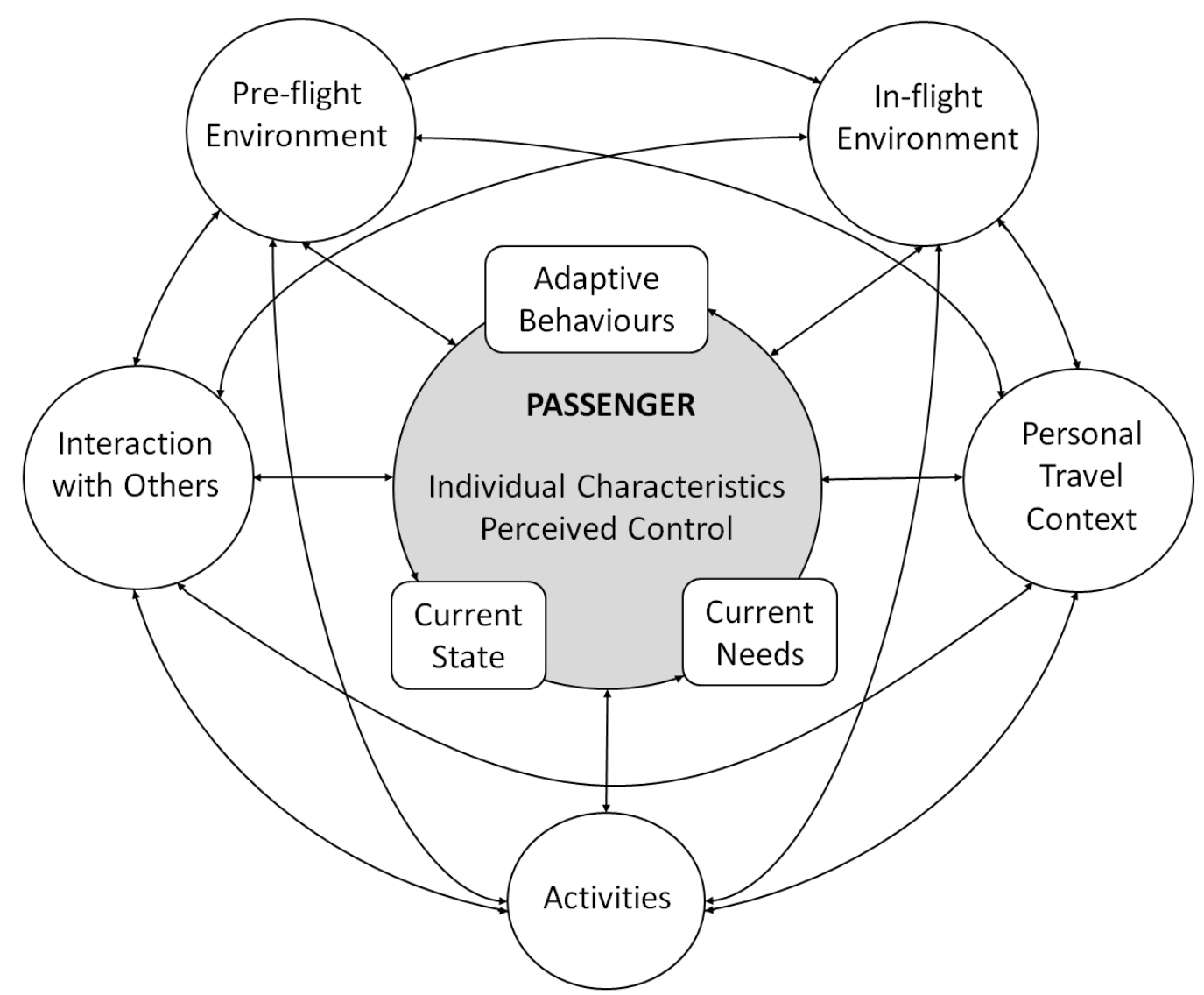

Figure 1. Model of key factors which influence aircraft passengers' comfort

Unlike other relevant models such as Mayr's model of riding comfort (1959), we have considered the role of passengers' activities on their experience of comfort (similarly to Ahmadpour et al., 2014a) and recognise the roles that activities may play as an aspect of adaptive behaviour when discomfort is experienced. We have acknowledged not only the changing state of a passenger but also their changing needs throughout a flight's duration. Also, drawing on Vink and Brauer's (2011) work, we include the pre-flight environment as a potential influence on in-flight comfort. In addition to riding comfort (within a vehicle), Mayr (1959) considered overall travelling comfort which includes local comfort - the equivalent of our pre-flight environment (e.g. comfort experienced at terminals) and organisational comfort (e.g. reliability) which is similar to factors we discuss under personal travel context. Similarly to Ahmadpour et al. (2014a), our review suggests that the psychological aspects of comfort are key to the overall comfort experienced and may be more important than physical factors.

Most studies on air service quality (e.g. Chang \& Yeh, 2002; Park, 2007) have mentioned comfort explicitly only with regards to seat comfort, although some studies have incorporated the aircraft interior (Pakdil \& Aydin, 2007) as well as entertainment and cleanliness (Jou, 
Lam, Hensher, Chen, \& Kuo, 2008). However, all of the elements included in SERVQUAL (Parasuraman et al., 1988) and adapted versions of the tool for this domain (e.g. legroom, catering, personal attention from crew, information etc.) can potentially influence comfort. Although other passengers can be included in SERVQUAL's 'tangible' dimension, studies have not examined the effect of these passengers on comfort or how they may change perceptions of service quality. There has also been no consideration of changing passengers' needs, their adaptive behaviours, activities and their perceived control over meeting their needs, all of which may influence overall perceived service quality and comfort.

Further, in studies using SERVQUAL, seat comfort has been incorporated in the 'tangible' dimension (Chou et al., 2011) and in the 'reliability and assurance' dimension (Pakdil \& Aydin, 2007) therefore it is not as clear-cut as categorising comfort as a tangible or intangible dimension. We argue that the experience of comfort is psychological and therefore it is an intangible outcome influenced by tangible and intangible elements of a passenger's personal travel context, their activities, pre-flight and in-flight environments and interaction with others.

The experience of discomfort starts when a passenger's physical, physiological, psychological or social needs are not being met. Different individuals will focus their attention on discomfort to varying levels and their ability to distract themselves from discomfort will also vary. Further, some sources of discomfort may be harder to overcome than others (e.g. a baby crying). There are differences in individual sensitivities to discomfort and this may vary within an individual depending on their personal travel context, perceived control over meeting their needs and so on. An individual's experience of comfort or discomfort may also be transient and affected by a combination of factors which may change over a flight's duration. For example, restricted legroom and unwanted noise may lead to increasing discomfort as a flight goes on.

\section{Conclusions}

Air passenger comfort is a complex and challenging area of study which has received surprisingly little attention in the literature. However, it is becoming increasingly important as demand for air travel rises and passenger experience becomes a key future economic driver.

One area requiring more attention is the influence of other people on comfort. Whilst there is much anecdotal evidence about the effect of others on comfort, there has been little structured research on how other passengers contribute to discomfort (or comfort) and the strategies that people use to manage or overcome this discomfort. A deeper understanding of these issues may feed into new design solutions to enhance comfort, whilst maintaining affordable travel.

As the experience of comfort itself is psychological, any intervention that can positively change how a person perceives a sub-optimal situation and/or provides options to improve the situation can help to increase comfort. There are therefore opportunities for aircraft manufacturers and airlines to introduce upgrades to existing aircrafts which may have wideranging positive effects. For example, comfort can be enhanced by implementing physical solutions such as changing the appearance of a seat, carefully designed visual experiences and 
offering passengers more choice in IFE systems, giving them more control over how they can pass their time.

Airlines and aircraft manufacturers are also increasingly investigating ways to personalise the passenger experience; for example, by dividing concept air cabins into different activity zones, such as entertainment, relaxation and working zones, to meet specific needs (Airbus, 2011); and by measuring passengers' mental state during a flight using neuro-sensors and a fibre optic blanket with a view to enhancing cabin service for individual passengers - the blanket displays different colours depending on how relaxed an individual is, allowing the crew to respond appropriately (Cabin Design \& Interiors, 2014). There are also opportunities for psychosocial interventions to improve comfort, such as videos or signage throughout the air transportation system to promote a universal passenger code of conduct, which could potentially improve service delivery and passenger comfort.

Our model of the factors that constitute and affect aircraft passenger comfort can be used to structure the design and evaluation of interventions, highlighting the different levels at which comfort can be influenced. In the future this could be used as a basis to create a 'comfort profile' for individual passengers to help personalise their flight experience. Understanding the passenger-centric factors influencing comfort can also help designers to enhance comfort in other modes of transport.

\section{Disclosure statement}

No potential conflict of interest was reported by the authors.

\section{References}

Abelson, J.L., Khan, S., Liberzon, I., Erickson, T.M., \& Young, E.A. (2008). Effects of perceived control and cognitive coping on endocrine stress responses to pharmacological activation. Biological Psychiatry, 64, 701-707.

Adey, P. (2008). Aeromobilities: Geographies, subjects and vision. Geography Compass, 2(5), 1318-1336.

Adey, P. \& Lin, W. (2014). Social and cultural geographies of air transport. In A.R. Goetz and L. Budd (Eds.), The Geographies of Air Transport (pp.61-71). Ashgate.

Ahmadpour, N., Lindgaard, G., Robert, J.-M., \& Pownall, B. (2014a). The thematic structure of passenger comfort experience and its relationship to the context features in the aircraft cabin. Ergonomics, 57, 801-815.

Ahmadpour, N., Robert, J.-M., \& Lindgaard, G. (2014b). Exploring the cognitive structure of aircraft passengers' emotions in relation to their comfort experience. In P. Lévy, S. Schütte, \& T. Yamanaka (Eds.), Proceedings of the International Conference on Kansei Engineering and Emotion Research, Linköping, 11-13 June, 2014, (pp.387-394). 
Ahmadpour, N., Kühne, M., Robert, J.M., and Vink, P. (2016). Attitudes towards personal and shared space during the flight. Work, 54(4), 981-987.

Airbus (2011). The Airbus concept cabin. Retrieved from http://www.airbus.com/innovation/future-by-airbus/the-concept-plane/the-airbus-conceptcabin/

Airbus (2013). Well-being and comfort. Retrieved from http://www.airbus.com/innovation/well-being/inside/

Alamdari, F. (1999). Airline in-flight entertainment: the passengers' perspective. Journal of Air Transport Management, 5, 203-209.

Andrews, L. (2010). 8 annoying types of travelers. Retrieved from http://www.airlinetickets.org/blog/8-annoying-types-of-travelers/

Balcombe, K., Fraser, I., \& Harris, L. (2009). Consumer willingness to pay for in-flight service and comfort levels: A choice experiment. Journal of Air Transport Management, 15, 221-226.

Bhadra, D. (2009). You (expect to) get what you pay for: A system approach to delay, fare, and complaints. Transportation Research Part A, 43, 829-843.

Bird, G. (2011, June). Individual quest. Aircraft Interiors International, pp. 36-42.

Boerstra, A., Beuker, T., Loomans, M., \& Hensen, J. (2013). Impact of available and perceived control on comfort and health in European offices. Architectural Science Review, $56(1), 30-41$.

Bonetti, D., Johnston, M., Rodriguez-Marin, J., Pastor, M., Martin-Aragon, M., Doherty, E., \& Sheehan, K. (2001). Dimensions of perceived control: A factor analysis of three measures and an examination of their relation to activity level and mood in a student and cross-cultural patient sample. Psychology and Health, 16, 655-674.

Bor, R. (2007). Psychological factors in airline passenger and crew behaviour: A clinical overview. Travel Medicine and Infectious Disease, 5, 207-216.

Brager, G.S., \& de Dear, R. (2000). A standard for natural ventilation. ASHRAE Journal, 42(10), 21-28.

Brager, G.S., Paliaga, G., \& de Dear, R. (2004). Operable windows, personal control and occupant comfort. ASHRAE Transactions, 110(2), 17-35.

Brundrett, G. (2001). Comfort and health in commercial aircraft: a literature review. Journal of the Royal Society for the Promotion of Health, 121(1), 29-37.

Budd, L.C.S. (2011). On being aeromobile: airline passengers and the affective experiences of flight. Journal of Transport Geography, 19, 1010-1016. 
Budd, L., Warren, A., \& Bell, M. (2011). Promoting passenger comfort and wellbeing in the air: An examination of the in-flight health advice provided by international airlines. Journal of Air Transport Management, 17, 320-322.

Burns, D. (2008). 10 types of airline passengers - which one are you? Retrieved from http://www.consumertraveler.com/columns/10-types-of-airline-passengers-which-one-areyou/

Butler, D.S., \& Moseley, G. L. (2003). Explain Pain. Adelaide: Noigroup Publications.

Cabin Design \& Interiors (2014). British Airways measures passengers' moods with 'happiness blanket'. Retrieved from http://www.futuretravelexperience.com/2014/07/britishairways-measures-passengers-moods-happiness-blanket/

Cascioli, V., Heusch, A.I., \& McCarthy, P.W. (2011). Does prolonged sitting with limited legroom affect the flexibility of a healthy subject and their perception of discomfort? International Journal of Industrial Ergonomics, 41, 471-480.

Chang, Y.-H., \& Yeh, C.H. (2002). A survey analysis of service quality for domestic airlines. European Journal of Operational Research, 139, 166-177.

Chen, F.-Y., \& Chang, Y.-H. (2005). Examining airline service quality from a process perspective. Journal of Air Transport Management, 11, 79-87.

Chou, C.-C., Liu, L.-J., Huang, S.-F., Yih, J.-M., \& Han, T.-C. (2011). An evaluation of airline service quality using the fuzzy weighted SERVQUAL method. Applied Soft Computing, 11, 2117-2128.

Cole, R.J., Robinson, J., Brown, Z., \& O'Shea, M. (2008). Re-contextualizing the notion of comfort. Building Research \& Information, 36, 323-336.

Corlett, E.N. (2005). The evaluation of industrial seating. In J.R. Wilson \& N. Corlett (Eds.), Evaluation of Human Work (pp. 729-742). Boca Raton, FL: CRC Press.

Cronian, D. (2009). The most annoying types of airline passengers. Retrieved from http://www.travel-rants.com/2009/10/15/most-annoying-passengers/

Crowe, A. (2010). The worst type of airline passengers. Retrieved from http://www.dailyfinance.com/2010/03/04/the-worst-type-of-airline-passengers/

Cwerner, S. Kesselring, S., \& Urry, J. (Eds.) (2008). Aeromobilities. Taylor \& Francis.

Dahlquist, L.M., McKenna, K.D., Jones, K.K., Dillinger, L., Weiss, K.E., \& Ackerman, C.S. (2007). Active and passive distraction using a head-mounted display helmet: Effects on cold pressor pain in children. Health Psychology, 26(6), 794-801.

De Looze, M.P., Kuijt-Evers, L.F.M., \& Van Dieen, J. (2003). Sitting comfort and discomfort and the relationships with objective measures. Ergonomics, 46, 985-997. 
Elliott, C. (2012). Which airline passengers drive you the craziest? Retrieved from http://continentaltravelgroup.com/journeys/which-airline-passengers-drive-you-the-craziest/

Evans, G.W., \& Cohen, S. (1987). Environmental stress. In D. Stokols \& I. Altman (Eds.), Handbook of Environmental Psychology (pp. 571-610). New York, NY: John Wiley \& Sons.

Evans, G.W., \& Wener, R.E. (2007). Crowding and personal space invasion on the train: Please don't make me sit in the middle. Journal of Environmental Psychology, 27, 90-94.

Fanger, P.O. (1970). Thermal comfort, analysis and applications in environmental engineering. New York, NY: McGraw-Hill.

Fiorella, S. (2011). 12 most annoying airline passenger personalities. Retrieved from http://12most.com/2011/06/22/12-annoying-airline-passenger-personalities/

Fried, M.L., \& DeFazio, V.J. (1974). Territoriality and boundary conflicts in the subway. Psychiatry, 37, 47-59.

Gardner, B. (2014). 'Knee defender' causing chaos on flights. Retrieved from http://www.telegraph.co.uk/news/aviation/11064259/Knee-defender-causing-chaos-onflights.html

Gilbert, D., \& Wong, R.K.C. (2003). Passenger expectations and airline services: a Hong Kong based study. Tourism Management, 24, 519-532.

Gountas, S., Ewing, M.T., \& Gountas, J.I. (2007). Testing airline passengers' responses to flight attendants' expressive displays: The effects of positive affect. Journal of Business Research, 60, 81-83.

Han, S.H., Jung, E.S., Jung, M., Kwahk, J., \& Park, S. (1998). Psychophysical methods and passenger preferences of interior designs. Applied Ergonomics, 29, 499-506.

Harris, C., \& Small, J. (2009). Obesity, tourism and discrimination? An investigation of airline 'customer of size' policies. In J. Carlsen, M. Hughes, K. Holmes, R. Jones (Eds.), CAUTHE 2009: See change: Tourism \& hospitality in a dynamic world (pp.1589-1608). Fremantle, W.A.: Curtin University of Technology.

Hayduk, L.A. (1983). Personal space: Where we now stand. Psychological Bulletin, 94, 293335.

Helander, M.G., \& Zhang, L. (1997). Field studies of comfort and discomfort in sitting. Ergonomics, 40, 895-915.

Hertzberg, H.T.E. (1958). Seat comfort. In: H. T. E. Hertzberg (Ed.), Annotated bibliography of applied physical anthropology in human engineering (WADC Technical report 56-30). Springfield: VA: Aero Medical Laboratory.

Hinninghofen, H., \& Enck, P. (2006). Passenger well-being in airplanes. Autonomic Neuroscience: Basic and Clinical, 129, 80-85. 
Horner, S., \& Swarbrooke, J. (2004). International cases in tourism management. Taylor \& Francis.

Howarth, P.A., \& Bullimore, M.A. (2005). Vision and visual work. In J.R. Wilson \& N. Corlett (Eds.), Evaluation of Human Work (pp. 573-604). Boca Raton, FL: CRC Press.

Howe, T. (2016) The true costs of heavier passengers. Retrieved from http://www.aircraftinteriorsinternational.com/articles.php?ArticleID=422

Jou, R.-C., Lam, S.-H., Hensher, D.A., Chen, C.-C., \& Kuo, C.-W. (2008). The effect of service quality and price on international airline competition. Transportation Research Part E, 44, 580-592.

Konieczny, G. (2001). Die messung und steigerung der qualität von dienstleistungen in der flugzeugkabine - Ein beitrag zur kundenorientierten flugzeugentwicklung - The measurement and improvement of quality of services in the aircraft cabin - a contribution to customerdriven aircraft development (Unpublished doctoral dissertation). Technische Universität Berlin, Germany.

Langevin, J., Wen, J., \& Gurian, P.L. (2012). Relating occupant perceived control and thermal comfort: Statistical analysis on the ASHRAE RP-884 database. HVAC\&R Research, 18(1-2), 179-194.

Leaman, A. (1999, March 4). Window seat or aisle? Studies of buildings in use are showing the importance of personal control of one's environment, which includes windows. Architects' Journal.

Lee, D., \& Luengo-Prado, M.J. (2004). Are passengers willing to pay more for additional legroom? Journal of Air Transport Management, 10, 377-383.

Little, K.B. (1965). Personal space. Journal of Experimental Social Psychology, 1, 237-247.

Mardiyono, M.N.S., Praneed Songwathana, R.N., \& Wongchan Petpichetchian, R.N. (2011). Concept analysis of perceived control. Nurse Media Journal of Nursing, 1, 225-243.

Mayr R. (1959). Comfort in Railway Travel. An examination of the fundamentals influencing vehicle design. The Railway Gazette, 3, 266-269.

Mellert, V., Baumann, I., Freese, N., \& Weber, R. (2008). Impact of sound and vibration on health, travel comfort and performance of flight attendants and pilots. Aerospace Science and Technology, 12, 18-25.

O'Neill, Martin A. (2004) Obesity and Air Travel: Weighing Up the Issues. Hospitality Review, 22(1), article 8.

Nikolopoulou, M., \& Steemers, K. (2003). Thermal comfort and psychological adaptation as a guide for designing urban spaces. Energy and Buildings, 35, 95-101. 
Oborne, D.J. (1978). Passenger comfort - An overview. Applied Ergonomics, 9(3), 131-136.

Pakdil, F., \& Aydin, O. (2007). Expectations and perceptions in airline services: An analysis using weighted SERVQUAL scores. Journal of Air Transport Management, 13, 229-237.

Parasuraman, A., Zeithaml, V.A., \& Berry, L.L. (1985). A conceptual model of service quality and its implications for future research. Journal of Marketing, 49, 41-50.

Parasuraman, A., Zeithaml, V.A., \& Berry, L.L. (1988). SERVQUAL: A multiple-item scale for measuring consumer perceptions of service quality. Journal of Retailing, 64(1), 12-40.

Park, J.-W. (2007). Passenger perceptions of service quality: Korean and Australian case studies. Journal of Air Transport Management, 13(4), 238-242.

Pennig, S., Quehl, J., \& Rolny, V. (2012). Effects of aircraft cabin noise on passenger comfort. Ergonomics, 55, 1252-1265.

Prideaux, B. and Seongseop, K. (2006). The relationship between airline cabin service and national culture: A cabin crew perspective. In: B. Prideaux, G. Moscardo and E. Laws (Eds.), Managing tourism and hospitality services: Theory and international applications. CABI.

Quehl, J. (2001). Comfort studies on aircraft interior sound and vibration. Aachen: Shaker Verlag GmbH.

Richards, L.G., \& Jacobson, I.D. (1974). Ride quality evaluation 1: Questionnaire studies of airline passenger comfort (Memorandum Report 403214 Short-Haul Air Transportation Program). Springfield, VA: National Technical Information Service.

Richards, L.G., Jacobson, I.D., \& Kuhlthau, A.R. (1978). What the passenger contributes to passenger comfort. Applied Ergonomics, 9(3), 137-142.

Roberts, D. (2014). Defending scarce leg space in flight: A right or grounds to sue? Retrieved from http://fortune.com/2014/09/10/knee-defender-airplane-blocker-legal-lawsuit-liability/

Santos, J. (2002). From intangibility to tangibility on service quality perceptions: a comparison study between consumers and service providers in four service industries. Managing Service Quality: An International Journal, 12(5), 292-302.

Scurr, J.R.H., Ahmad, N., Thavarajan, D. and Fisher, R.K. (2010). Traveller's thrombosis: airlines still not giving passengers the WRIGHT advice!

Phlebology, 25, 257-260.

Small, J., \& Harris, C. (2012). Obesity and tourism: Rights and responsibilities. Annals of Tourism Research, 39(2), 686-707.

Sommer, R. (1959). Studies in personal space. Sociometry, 22, 247-260.

Sommer, R. (2002). Personal space in a digital age. In R.B. Bechtel \& A. Churchman (Eds.), Handbook of Environmental Psychology (pp.647-660). New York, NY: John Wiley \& Sons. 
Suki, N.M. (2014). Passenger satisfaction with airline service quality in Malaysia: A structural equation modeling approach. Research in Transportation Business and Management, 10, 26-32.

Tajadura-Jiménez, A., Pantelidou, G., Rebacz, P., Västfjäll, D., \& Tsakiris, M. (2011). ISpace: The effects of emotional valence and source of music on interpersonal distance. PLoS ONE, 6(10): e26083. doi:10.1371/journal.pone.0026083.

Veldhuis, F and Holt, C. (n.d.). Too fat to fly?

http://www.aircraftinteriorsinternational.com/articles.php?ArticleID=484

Vink, P., Bazley, C., Kamp, I., \& Blok, M. (2012). Possibilities to improve the aircraft interior comfort experience. Applied Ergonomics, 43, 354-359.

Vink, P., \& Brauer, K. (2011). Aircraft Interior Comfort and Design. Boca Raton, FL: CRC Press.

Vink, P., \& Hallbeck, S. (2012). Editorial: Comfort and discomfort studies demonstrate the need for a new model. Applied Ergonomics, 43, 271-276.

Zhang, L., Helander, M., \& Drury, C.G. (1996). Identifying factors of comfort and discomfort in seating. Human Factors, 38, 377-389. 